\title{
Fetal Growth Restriction
}

\section{Kazuo Maeda*}

Department of Obstetrics and Gynecology (Emeritus), Tottori University Medical School, Yonago, Japan

A fertilized human ovum grows up to the morula and blastula then go through the Fallopian tube to the uterine cavity, where the blastula implanted into the thick endometrium, then forms a placenta, by which obtains nourishments from maternal blood via the chorionic tissue of placental villi, which has special ability in the active transfer of nutritive material from maternal blood, e.g. glucose concentration of fetal blood is higher than maternal blood, i.e. nutritive material is actively transferred by the chorionic tissue. The active transfer function may be diminished in Fetal Growth Restriction (FGR). The fetal weight estimated by ultrasound biometry, usually by the biparietal diameter of fetal head (BPD) or head circumference, Femur Length (FL) and abdominal diameter or circumference (AC) is smaller than normal growth fetus, and the birth weight is small for gestational age (SGA). The SGA neonate not only faces various health problems, high risk to sickness and nutritional problem, it is probably to accompany the development of sickness in adult age [1]. The placenta villi transfer oxygen $\left(\mathrm{O}_{2}\right)$ and carbon dioxide $\left(\mathrm{CO}_{2}\right)$ passively according to gradients between maternal and fetal blood. Placental active transfer function diminishes resulting fetal weight reduction and FGR according to the damage of villi in the fibrin deposit in the intervillous space e.g. in maternal positive phospholipid antibody. Initially the nutritive material transfer is diminished to reduce fetal growth, and then the transfer of maternal oxygen to the fetus diminishes in the progress of placental villi damages, producing fetal hypoxia, non-reactive FHR and NRFS, then finally fetal demise is possible in the highest fetal hypoxia. The echogenicity of ultrasound B-mode placental image increased looks white, accompanying FGR in the fibrin deposit inintervillous space, and the ultrasound GLHW, which is clinical tissue characterization, is elevated. In actocardiogram, the FGR fetus, who showed the nonreactive FHR by the loss of FHR acceleration against fetal movement bursts, but preserving FHR baseline variability, showed heavy hypoxic signs of NRFS some days later,with the bradycardia, late deceleration and the loss of FHR variability. Neonatal outcome of FGR in NRFS was ominous, showing heavy asphyxia and sometimes neonatal death even after Cesarean section. The outcome was worse comparing to the normal reassuring FGR cases of positive FHR acceleration [2]. A nonreactive FGR may be better to receive C-section before heavy asphyxia. Also, the NST, FHR monitoring in pregnancy, is mandatory in the FGR fetus. The treatment of fibrin deposit in intervillous space was the solution of fibrin by the heparin administration. In our experience, the $2^{\text {nd }}$ trimester FGR, whose estimated fetal weight was small, the GLHW was high, and the antibody was positive. The fetus of previous pregnancy was FGR and died. Dr. Utsu administered heparin for 5,000 U every day, then estimated fetal weight increased to normal, GLHW lowered to normal, then normal neonate was obtained [3]. There will be other causes of FGR also, which will be maternal hyponutrition, maternal disease, maternal cigarette smoking, maternal heavy drinking, multiple pregnancy, fetal congenital abnormality, or fetal infectious diseases. Pregnant women should be careful on her own nutrition and health status with the purpose to prevent FGR. Possible treatment of FGR differs according to its cause, where maternal smoking and drinking should be stopped during pregnancy not only for the health of pregnant women, but also for the normal fetal growth. The fetal alcoholic syndrome is prevented also by stopping drinking. Since the pregnancy is a pre-pathologic situation, e.g. fetal $\mathrm{PaO}_{2}$ is usually $50 \mathrm{mmHg}$ or low, which is a hypoxic condition when it is evaluated with adult $\mathrm{PaO}_{2}$ level, pregnant women should live under close medical environment such as frequent visits with NST and sonography, in addition with carefulselfmanagement.

\section{References}

1. Cesar G Victora, Linda Adair, Caroline Fall, Pedro C Hallal, Reynaldo Martorell, et al. (2008) Maternal and child undernutrition: consequences for adult health and human capital. Lancet 371: 340-357.

2. Teshima N (1993) Non-reactive pattern diagnosed by ultrasonic Doppler fetal actocardiogram and outcome of the fetuses with non-reactive pattern. Nihon SankaFujinkaGakkaiZasshi 45: 423-430.

3. Maeda K, Utsu M, Kihaile PE (1998) Quantification of sonographic echogenicity with grey-level histogram width: A clinical tissue characterization. Ultrasound Med Biol 24: 225-234.
*Corresponding author: Kazuo Maeda, Department of Obstetrics and Gynecology (Emeritus), Tottori University Medical School, Yonago, Japan, 3-125, Nadamachi, Yonago, Tottoriken, 6830835, Japan, Tel: 81-859-22-6856; Fax: 81-859-22-6856; E-mail: maeda@mocha.ocn.ne.jp

Received January 13, 2014; Accepted January 15, 2014; Published January 20 2014

Citation: Maeda K (2014) Fetal Growth Restriction. J Health Med Informat. 5 : e120. doi:10.4172/2157-7420.1000e120

Copyright: ( 2014 Maeda K. This is an open-access article distributed under the terms of the Creative Commons Attribution License, which permits unrestricted use, distribution, and reproduction in any medium, provided the original author and source are credited. 